\title{
Does anti-reflux surgery disrupt the pathway of Barrett's esophagus progression to cancer?
}

\author{
Sebastian F. Schoppmann ${ }^{1}$, Ivan Kristo ${ }^{1}$, Martin Riegler ${ }^{2}$ \\ ${ }^{1}$ Department of Surgery, Medical University of Vienna, and Gastroesophageal Tumor Unit, Comprehensive Cancer Centre (CCC), Vienna, Austria; \\ ${ }^{2}$ Reflux Medical, Vienna, Austria \\ Contributions: (I) Conception and design: SF Schoppmann; (II) Administrative support: SF Schoppmann; (III) Provision of study material or patients: \\ SF Schoppmann; (IV) Collection and assembly of data: SF Schoppmann, M Riegler; (V) Data analysis and interpretation: SF Schoppmann, M \\ Riegler; (VI) Manuscript writing: All authors; (VII) Final approval of manuscript: All authors. \\ Correspondence to: Sebastian F. Schoppmann, FACS. Department of Surgery, Medical University of Vienna, and Gastroesophageal Tumor Unit, \\ Comprehensive Cancer Center, Spitalgasse 23, 1090 Vienna, Austria. Email: sebastian.schoppmann@muv.ac.at.
}

\begin{abstract}
In patients with Barrett's esophagus (BE), anti-reflux surgery aims to sustainable control reflux symptoms and heal reflux induced esophageal mucosal inflammation and prevent progression of BE to adenocarcinoma. There is growing evidence that beside gastric acid, bile salts in refluxed duodenal juice are responsible for the development and progression of BE. However, the pathogenesis of BE progression and the metaplasia-dysplasia-carcinoma sequence of the adenocarcinoma of the esophagus (EAC) is multifactorial and occurs over long natural time course. After anti-reflux surgery significant levels of regression from metaplastic Barrett's to non-metaplastic epithelium as well as from dysplastic to non-dysplastic BE have been observed and a randomized trial showed that sufficient surgical reflux control reduces the risk of Barrett's progression significantly when compared to medical treatment. Thus, large cohort studies show significant reduced risk of EAC in patients suffering from gastroesophageal reflux disease (GERD) with and without $\mathrm{BE}$ after anti-reflux surgery. Even after anti-reflux surgery the risk for EAC remains elevated in patients with $\mathrm{BE}$ and the right moment of intercepting the progressive nature of GERD has to be discussed in future. The paper also addresses the impact of anti-reflux surgery, endoscopic ablation and life style therapies for the management of GERD, BE and cancer prevention.
\end{abstract}

Keywords: Anti-reflux surgery; Barrett's esophagus (BE); esophageal adenocarcinoma

Received: 11 August 2018; Accepted: 28 September 2018; Published: 05 December 2018.

doi: $10.21037 / \operatorname{tgh} .2018 .11 .07$

View this article at: http://dx.doi.org/10.21037/tgh.2018.11.07

\section{Introduction}

Incidences of adenocarcinoma of the esophagus have dramatically risen over the past decades and despite significant improvements in the medical and surgical treatment all over 5-year survival rate remain below $30 \%$ and prevention strategies are urgently needed (1-3).

Gastroesophageal reflux disease (GERD) is believed to be responsible for more than $60 \%$ of esophageal adenocarcinomas whereas patients with weekly reflux symptoms are known to have a 7 -fold increased risk for developing adenocarcinoma (4). Around $12 \%$ percent of patients with chronic GERD develop mucosal metaplasia so called Barrett's esophagus (BE) which is, via low- and highgrade dysplasia, associated with an up to 125 -fold increased risk for esophageal adenocarcinoma $(5,6)$.

$B E$, the only known precursor for esophageal adenocarcinoma, is a potentially reversible conditions if the reflux-induced chronic inflammatory process is treated effectively (7-9). This short review brings together data we have on the discussion if anti-reflux surgery can be expected to disrupt the pathway of $\mathrm{BE}$ and with this the development of esophageal adenocarcinoma. 


\section{Pathogenesis of Barrett development}

Despite various theories, the pathogenesis of $\mathrm{BE}$ is still poorly understood. Direct extension of gastric cells adjacent to the esophagus, reprogramming of squamous stem cells or repopulation from submucosal esophageal glands are discussed as origin of the metaplastic columnar Barrett's epithelium (10). Traditionally, acid reflux was considered playing the main role in the pathogenesis of BE (11). However, evidence is growing that rather chronic, cytokine mediated inflammation of the distal esophagus than chemical injury from acid reflux alone is significant for the development of metaplastic epithelium $(12,13)$.

Further it was shown that duodenogastro-oesophageal reflux including low $\mathrm{pH}$ and bile acids both increase the risk of epithelial erosion and are independent risk factors for the development of BO (14).

Under normal physiologic gastric conditions, bile acids irreversibly precipitate and are of minimal significance but in a more alkaline gastric environment, as found in patients under acid-suppression medication, bile salts are mainly dissociated and more likely to cause cellular damage bile acids cause DNA damage (15). Dissociated bile salts are further thought to, which can prevent the apoptosis that should be induced by DNA damage, enabling Barrett's cells that have sustained potentially carcinogenic genetic alterations to survival (16).

Various studies in rat reflux models that have been established as validated and reproducible models for the development of BE and EAC showed that reflux of a mixture of acid and bile components results in a PPI independent induction of chronic inflammation, BE and EAC (17).

In patients with GERD an increased exposure of a mixture of acid and bile was clearly associated with progressed GERD disease (long-segment BE and early EAC) (18).

Conceptually, dysfunction of the lower esophageal sphincter fosters increased gastro-esophageal reflux, which in turn provokes a neurohumoral-orchestration-induced inflammatory response in the esophagus, involving immune cells, nerve cells, fibroblasts (19). This neurohumoral flush stimulates genetic, cellular and functional changes leading to the development of columnar lined esophagus and $\mathrm{BE}$. Thus, not the gastric acid, not the reflux per se represents the cause of GERD and BE. In contrast to that, the dysfunction of the lower esophageal sphincter and the loosening of its fixation and attachments within the diaphragm (i.e., hiatal geometry) are to be regarded as the cause of the disease (20). Consequently it seems reasonable to consider, that effective anti-reflux surgery and repair of the hiatus (hiatal closure) may contribute to normalize reflux and prevent the progression of $\mathrm{BE}$ to cancer. Going in line with this suggestions, recent studies demonstrated that dysfunction of the lower esophageal sphincter i.e., shortened abdominal $(<1.0 \mathrm{~cm})$ and total lower LES length $(<2.0 \mathrm{~cm})$; decreased LES pressure $(\leq 6.0 \mathrm{mmHg})$ positively correlated with increased reflux and the presence of BE (21-24). Furthermore, the correlation of endoscopic and function test data demonstrated a positive association between increased dysfunction of the lower esophageal sphincter, acid exposure and higher Hill grade of the esophagogastric valve (25). The Hill valve represents a valuable endoscopic marker for the integrity of the geometry of the esophagus within the hiatus of the diaphragm. Multiple studies have demonstrated that effective anti-reflux surgery repairs the dysfunction of the lower esophageal sphincter and normalizes the geometry of the diaphragmatic hiatus (26-28). In addition, effective anti-reflux surgery assures, that patients do not require proton pump inhibitor therapy, which alters the $\mathrm{pH}$ of the reflux, i.e., towards more alkaline $\mathrm{Ph}$ (29). This in fact has been demonstrated to create a $\mathrm{pH}$ gradient across the squamocolumnar junction within the esophagus, which changes the biochemical characteristics of the bile salts (see above), which in turn stimulates the development of BE, dysplasia and cancer-i.e., up to 10 folds increased risk for cancer development in persons with chronic PPI therapy (30).

\section{Effect of anti-reflux surgery on BE}

Based on these observations, various clinical studies evaluating the effect of anti-reflux surgery on the progression of $\mathrm{BE}$ and risk of EAC have been published (see Table 1).

The two nationwide and population-based cohort studies comparing the risk of developing EAC in patients after antireflux surgery to that of the background population from Sweden and Finland, published in 2010 and 2011, included more than 250,000 and 160,000,000 person-years of follow in the anti-reflux surgery group and in the background group, respectively (31-33). As expected meta-analysis of these two studies showed a significant increased risk of EAC for patients in the anti-reflux surgery (GERD-group) [IRR 10.78 (95\% CI: 8.48-13.71)] (33).

Meta-analysis comparing medical treated versus surgical treated GERD patients $(100,479$ person-years in the anti- 
Table 1 Studies with anti-reflux surgery in patients with Barrett's esophagus

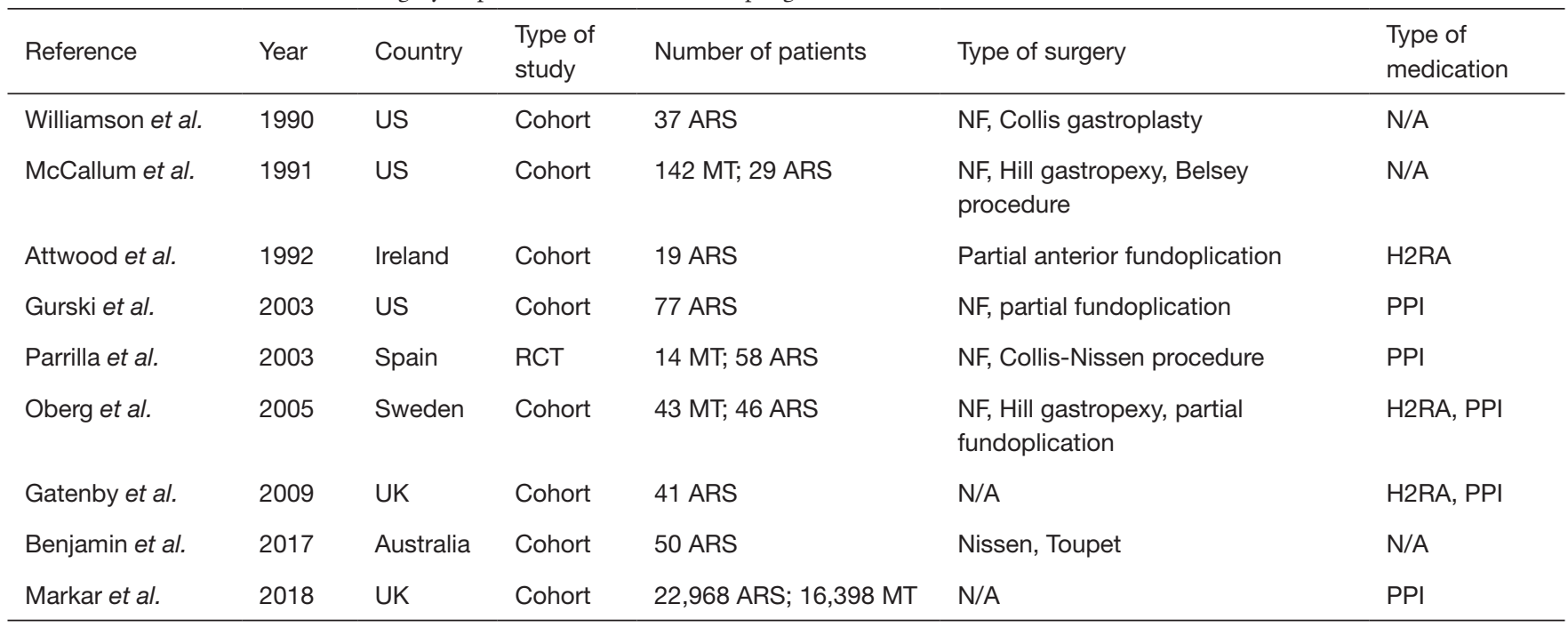

NF, Nissen fundoplication; PPI, proton pump inhibitors, RCT, randomized controlled trial; ARS, anti-reflux surgery; H2RA, H2-receptorantagonist; HGD, high grade dysplasia; MT, medical treatment; N/A, not available.

reflux surgery group and 400459 person years in the nonsurgery group, respectively) revealed a decreased pooled IRR (IRR 0.89. 95\% CI: 0.66-1.19) comparing surgical with nonsurgical treated patients (34). Results of subgroup analysis of patients with GERD in the very recently published national population-based cohort study including more than 830,000 patients older than 18 years with GERD with around 3\% (around 22,200 patients) undergoing anti-reflux surgery more than support these observations presenting a statistical significant reduced risk of EAC for patients after anti-reflux surgery (HR 0.64; 95\% CI: 0.52-0.78) (35).

When analyzing the effect of anti-reflux surgery in patients with known BE, the results of a meta-analysis as well as subgroup analysis of a recently published cohort study from England including more than 28,000 patients with $\mathrm{BE}$, describe decreased risk of EAC for patients after anti-reflux surgery (IRR 0.26, 95\% CI: $0.09-0.79$ and HR 0.47, 95\% CI: 0.12-1.90) (31,36-38). These results for patients with and without $\mathrm{BE}$ where independent of patients age as revealed in subgroup analysis in patient aged 50 years or older (HR 0.75 ; $95 \%$ CI: $0.58-0.97$ and HR 0.76; 95\% CI: 0.19-3.09, respectively).

The anatomical, histopathological, functional, genetic and biochemical properties of $\mathrm{BE}$ are responsible for BEdependent, quality-defined difficulties and insecurities for the diagnosis and therapy of the disease. Most importantly the phenomenological interpretation of morphological and functional changes, which parallel the development of NERD, GERD, BE, dysplasia and cancer, reveals a particular spectrum of diagnostic shortcomings due to inadequately assessable and-although technologies profoundly improved-still inaccurately definable changes, alterations and processes within the course of the disease (39). As such we do not know, if the genetic, cellular and biochemical changes responsible for cancer development have already been activated before anti-reflux surgery. Ringhofer et al. have demonstrated a patchy distribution of cardiac mucosa, non-dysplastic and dysplastic Barrett's mucosa within a given segment of columnar lined esophagus (40). As a consequence, biopsy error may lead to under or over grading of BE. In addition, there exists no universal agreement regarding the morphological and function (manometry, $\mathrm{pH}$ monitoring data) definition of successful anti-reflux surgery. Moreover, patients are referred to anti-reflux surgery, when medical therapy has failed. As a consequence the large majority of these patients present for surgery at advanced stage of the disease, i.e., long history of GERD symptoms, large hiatal hernia, severe esophagitis, long segments of columnar lined esophagus $( \pm \mathrm{BE})$, failure of the sphincter and esophageal transport function and abnormal reflux monitoring. As mentioned above and below, these qualities define the typical and characteristic profile for an increased cancer risk in patients with GERD and BE. Thus, patients have already drawn bad cards to start with, when being seen by the surgeon. Here, interdisciplinary communication between the gastroenterologist and the 
surgeon is mandatory for definition and detection of those patients who benefit from early intervention prior to cancer development. The open-minded approach serves cancer prevention and requires a holistic, tailored approach towards diagnosis, therapy and disease management. Taken together, the above listed disease dependent qualities and characteristics (i.e., staging, genetics etc.) support early intervention in the course of the disease in order to minimize the risk for cancer development.

Remains to be questioned to combine anti-reflux surgery and radiofrequency ablation for cancer prevention in individuals with GERD and BE $(7,41)$. Radiofrequency ablation represents a novel endoscopic technology for durable elimination of $\mathrm{BE}$ ( \pm dysplasia and cancer) and has been demonstrated to prevent cancer development in persons with early cancer, high-grade and low-grade dysplasia $(42,43)$. The cancer preventive effect of RFA in persons with non-dysplastic BE awaits further proof. However, data justify to offer RFA to persons with nondysplastic BE and increased cancer risk profile (i.e., GERD more than 10 years, positive family history for esophageal cancer, large hiatal hernia, esophagitis, history of dysplastic BE) (44). Conceptually, RFA \pm endoscopic mucosal resection of BE tissue can be offered before, during or after anti-reflux surgery. At present there exist long no data addressing this issue. However, the group around Skrobić and Simic et al. demonstrated that the combination of anti-reflux surgery and RFA may be cancer preventive in $\mathrm{BE}$ positive persons with advanced disease, i.e., high volume reflux, large hiatal hernia, esophagitis (45). The results of future studies are to be awaited for allowing a definitive recommendation.

The above findings show that there exists a rapidly growing evidence that, in addition to the elimination GERD symptoms, anti-reflux surgery contributes to prevent the progression of $\mathrm{BE}$ to cancer. Remains to be questioned, who should get the therapies for cancer prevention in GERD and BE and when they should be scheduled during the course of the disease. Thus it seems crucial to define those at increased cancer risk and the ideal time point for the intervention (surgery, ablation etc.).

Patient selection aims to define those who will maximally benefit from the treatment, i.e., those at direct or indirect cancer risk. First of all, the diagnosis of GERD and BE should include cautious patient history, endoscopy, biopsy sampling, histopathology (Chandrasoma classification), esophageal manometry and reflux monitoring $(46,47)$. These tests contribute to assess the presence or absence of specific risk factors (see below). Conceptually those with increased cancer risk will benefit from the elimination of reflux and cancer risk. BE positive columnar lined esophagus containing early cancer, high and low grade dysplasia represent stages with increased cancer risk and should be treated by ablative therapies, i.e., RFA, EMR and subsequent anti-reflux surgery (for symptom control). Bridging until anti-reflux surgery should include a proton pump inhibitor (PPI) therapy. BE without dysplasia allows different approaches. Persons with non-dysplastic BE are at increased cancer risk, i.e., equal to low grade dysplasia, if the following criteria are fulfilled: long standing GERD ( $>10$ years), endoscopic visible esophagitis, tongues of columnar lined esophagus exceeding $2.0 \mathrm{~cm}$, large hiatal hernia $(>3.0 \mathrm{~cm})$ and a family history positive for esophageal and/or gastric cancer (44). Therefore patients with the above risk profile also benefit from RFA for non-dysplastic BE, i.e., in patients with the above risk profile, non-dysplastic BE harbors the cancer risk of low grade dysplasia.

Going in line with the novel understanding of the pathogenesis underlying GERD and BE, effective management should target the elimination of the cause, i.e., the reflux, and target the manifestation, i.e., BE. Thus, it seems justified to consider the combination of anti-reflux surgery and endoscopic therapies $(\mathrm{RFA} \pm \mathrm{EMR})$ for those with non-dysplastic BE and increased cancer risk (above risk profile). As suggested above, the evidence based proof for the ideal sequence of the treatments has not yet been found. Basically, for non-dysplastic BE, anti-reflux surgery can be offered before, during or after RFA (48). Therefore nondysplastic BE may be managed by anti-reflux surgery first or RFA first or both treatments at the same time. Remains to be questioned the ideal time point for the treatment of GERD and BE for cancer prevention.

Progression of disease, i.e., non-dysplastic to dysplasia, or low to high grade etc. should be managed by ablation of premalignant tissue. Progression of cardiac mucosa positive CLE to goblet cell positive CLE, i.e., BE, may be treated by anti-reflux surgery and RFA (at the same time or subsequently). Based on the above considerations, the ideal time point for the intervention seems to be the progression from cardiac mucosa to non-dysplastic BE during follow up. Future studies will have to proof the value of this approach.

Anti-reflux surgery harbors considerable side effects (gas bloat, dysphagia, break down, failure, slipping) including the relapse of GERD and BE (49). Risk factors for failure of anti-reflux surgery include impaired esophageal function, normal pre-surgical esophageal function test, normal 
esophageal function and reflux monitoring (+ absence of positive symptom correlation). As such, accurate preoperative diagnosis including endoscopy and function tests help to define those, who will benefit from the anti-reflux surgery, i.e., those with LES dysfunction and abnormal reflux monitoring. In addition, it is essential, that the procedures are conducted in centers with high volume experience in the full spectrum diagnosis, treatment and follow up of GERD and BE (44). Finally life style aspects should be implemented into the management of GERD and BE. Future studies will have to proof in as much nutrition contributes to cancer prevention and to support anti-reflux surgery and endoscopic therapies for the management of GERD and BE.

\section{Conclusions}

Taken together, increasing evidence justifies to assume that effective anti-reflux surgery and ablative endoscopic therapy contribute to disrupt the progression of $\mathrm{BE}$ to cancer. Accurate diagnosis and tailored therapy seem mandatory for effective cancer prevention. Future studies will have to proof the value of novel cancer prevention concepts. A tailored, interdisciplinary approach seems mandatory for cancer prevention in GERD and BE. May these aspects motivate the "act" vs. "wait and see" policy for disease management.

\section{Acknowledgements}

None.

\section{Footnote}

Conflicts of Interest: The authors have no conflicts of interest to declare.

\section{References}

1. Davies AR, Gossage JA, Zylstra J, et al. Tumor stage after neoadjuvant chemotherapy determines survival after surgery for adenocarcinoma of the esophagus and esophagogastric junction. J Clin Oncol 2014;32:2983-90.

2. Zhang Y. Epidemiology of esophageal cancer. World J Gastroenterol 2013;19:5598-606.

3. Gupta V, Coburn N, Kidane B, et al. Survival prediction tools for esophageal and gastroesophageal junction cancer: A systematic review. J Thorac Cardiovasc Surg
2018;156:847-56.

4. Pandeya N, Webb PM, Sadeghi S, et al. Gastrooesophageal reflux symptoms and the risks of oesophageal cancer: are the effects modified by smoking, NSAIDs or acid suppressants? Gut 2010;59:31-8.

5. Peng S, Huo X, Rezaei D, et al. In Barrett's esophagus patients and Barrett's cell lines, ursodeoxycholic acid increases antioxidant expression and prevents DNA damage by bile acids. Am J Physiol Gastrointest Liver Physiol 2014;307:G129-39.

6. Sharma P. Clinical practice. Barrett's esophagus. N Engl J Med 2009;361:2548-56.

7. Kristo I, Asari R, Rieder E, et al. Treatment of Barrett's esophagus: update on new endoscopic surgical modalities. Minerva Chir 2015;70:107-18.

8. Schlottmann F, Molena D, Patti MG. Gastroesophageal reflux and Barrett's esophagus: a pathway to esophageal adenocarcinoma. Updates Surg 2018;70:339-42.

9. Spechler SJ, Souza RF. Barrett's esophagus. N Engl J Med 2014;371:836-45.

10. McDonald SA, Lavery D, Wright NA, et al. Barrett oesophagus: lessons on its origins from the lesion itself. Nat Rev Gastroenterol Hepatol 2015;12:50-60.

11. Inadomi J, Alastal H, Bonavina L, et al. Recent advances in Barrett's esophagus. Ann N Y Acad Sci 2018. [Epub ahead of print].

12. Dunbar KB, Agoston AT, Odze RD, et al. Association of Acute Gastroesophageal Reflux Disease With Esophageal Histologic Changes. JAMA 2016;315:2104-12.

13. Souza RF, Huo X, Mittal V, et al. Gastroesophageal reflux might cause esophagitis through a cytokinemediated mechanism rather than caustic acid injury. Gastroenterology 2009;137:1776-84.

14. Farré R, Fornari F, Blondeau K, et al. Acid and weakly acidic solutions impair mucosal integrity of distal exposed and proximal non-exposed human oesophagus. Gut 2010;59:164-9.

15. Di Ciaula A, Wang DQ, Molina-Molina E, et al. Bile Acids and Cancer: Direct and Environmental-Dependent Effects. Ann Hepatol 2017;16:s87-s105.

16. Jenkins GJ, Cronin J, Alhamdani A, et al. The bile acid deoxycholic acid has a non-linear dose response for DNA damage and possibly NF-kappaB activation in oesophageal cells, with a mechanism of action involving ROS. Mutagenesis 2008;23:399-405.

17. Greene CL, Worrell SG, DeMeester TR. Rat Reflux Model of Esophageal Cancer and Its Implication in Human Disease. Ann Surg 2015;262:910-24. 
18. Stein HJ, Feith M, Feussner H. The relationship between gastroesophageal reflux, intestinal metaplasia and adenocarcinoma of the esophagus. Langenbecks Arch Surg 2000;385:309-16.

19. Rieder E, Riegler M, Simic AP, et al. Alternative therapies for GERD: a way to personalized antireflux surgery. Ann N Y Acad Sci 2018. [Epub ahead of print].

20. Schwameis K, Nikolic M, Castellano DGM, et al. Crural Closure improves Outcomes of Magnetic Sphincter Augmentation in GERD patients with Hiatal Hernia. Sci Rep 2018;8:7319.

21. Bonavina L, Saino GI, Bona D, et al. Magnetic augmentation of the lower esophageal sphincter: results of a feasibility clinical trial. J Gastrointest Surg 2008;12:2133-40.

22. Zaninotto G, DeMeester TR, Schwizer W, et al. The lower esophageal sphincter in health and disease. Am J Surg 1988;155:104-11.

23. Marshall RE, Anggiansah A, Anggiansah CL, et al. Esophageal body length, lower esophageal sphincter length, position and pressure in health and disease. Dis Esophagus 1999;12:297-302.

24. Stein HJ, Crookes PF, DeMeester TR. Three-dimensional manometric imaging of the lower esophageal sphincter. Surg Annu 1995;27:199-214.

25. Oberg S, Peters JH, DeMeester TR, et al. Endoscopic grading of the gastroesophageal valve in patients with symptoms of gastroesophageal reflux disease (GERD). Surg Endosc 1999;13:1184-8.

26. Ayazi S, Tamhankar A, DeMeester SR, et al. The impact of gastric distension on the lower esophageal sphincter and its exposure to acid gastric juice. Ann Surg 2010;252:57-62.

27. Ayazi S, DeMeester SR, Hsieh CC, et al. Thoracoabdominal pressure gradients during the phases of respiration contribute to gastroesophageal reflux disease. Dig Dis Sci 2011;56:1718-22.

28. Ayazi S, Hagen JA, Zehetner J, et al. Day-to-day discrepancy in Bravo $\mathrm{pH}$ monitoring is related to the degree of deterioration of the lower esophageal sphincter and severity of reflux disease. Surg Endosc 2011;25:2219-23.

29. Galmiche JP, Hatlebakk J, Attwood S, et al. Laparoscopic antireflux surgery vs esomeprazole treatment for chronic GERD: the LOTUS randomized clinical trial. JAMA 2011;305:1969-77.

30. Theodorou D, Ayazi S, DeMeester SR, et al. Intraluminal $\mathrm{pH}$ and goblet cell density in Barrett's esophagus. J Gastrointest Surg 2012;16:469-74.

31. Lagergren J, Ye W, Lagergren P, et al. The risk of esophageal adenocarcinoma after antireflux surgery. Gastroenterology 2010;138:1297-301.

32. DeMeester SR. Antireflux surgery and the risk of esophageal adenocarcinoma: an antithetical view of the data from sweden. Ann Surg 2013;257:583-5.

33. Maret-Ouda J, Konings P, Lagergren J, et al. Antireflux Surgery and Risk of Esophageal Adenocarcinoma: A Systematic Review and Meta-analysis. Ann Surg 2016;263:251-7.

34. Rickenbacher N, Kotter T, Kochen MM, et al. Fundoplication versus medical management of gastroesophageal reflux disease: systematic review and meta-analysis. Surg Endosc 2014;28:143-55.

35. Moore M, Afaneh C, Benhuri D, et al. Gastroesophageal reflux disease: A review of surgical decision making. World J Gastrointest Surg 2016;8:77-83.

36. Wiseman EF, Ang YS. Risk factors for neoplastic progression in Barrett's esophagus. World J Gastroenterol 2011;17:3672-83.

37. Gatenby P, Soon Y. Barrett's oesophagus: Evidence from the current meta-analyses. World J Gastrointest Pathophysiol 2014;5:178-87.

38. Löfdahl HE, Lu Y, Lagergren P, et al. Risk factors for esophageal adenocarcinoma after antireflux surgery. Ann Surg 2013;257:579-82.

39. Riegler M, Asari R, Cosentini EP, et al. Critical assessment of a new endoscopic anatomic concept for the so-called cardia in the sense of the notions of Parmenides and Martin Heidegger. Z Gastroenterol 2014;52:367-73.

40. Ringhofer C, Lenglinger J, Izay B, et al. Histopathology of the endoscopic esophagogastric junction in patients with gastroesophageal reflux disease. Wien Klin Wochenschr 2008;120:350-9.

41. Kristo I, Riegler M, Schoppmann SF. Should antireflux surgery be considered after successful endoscopic treatment of Barrett's esophagus with dysplasia and early cancer? Endoscopy 2016;48:92.

42. Pasricha S, Bulsiewicz WJ, Hathorn KE, et al. Durability and predictors of successful radiofrequency ablation for Barrett's esophagus. Clin Gastroenterol Hepatol 2014;12:1840-7.e1.

43. Shaheen NJ, Sharma P, Overholt BF, et al. Radiofrequency ablation in Barrett's esophagus with dysplasia. N Engl J Med 2009;360:2277-88.

44. Riegler M, Kristo I, Nikolic M, et al. Update on the management of Barrett's esophagus in Austria. Eur Surg 2017;49:282-7.

45. Skrobić O, Simic A, Radovanovic N, et al. Significance 
of Nissen fundoplication after endoscopic radiofrequency ablation of Barrett's esophagus. Surg Endosc 2016;30:3802-7.

46. Chandrasoma P. How the pathologist can aid in the assessment of gastroesophageal reflux disease. Curr Opin Gastroenterol 2018;34:233-42.

47. Spechler SJ, Katzka DA, Fitzgerald RC. New Screening Techniques in Barrett's Esophagus: Great Ideas or Great

doi: $10.21037 / \operatorname{tgh} .2018 .11 .07$

Cite this article as: Schoppmann SF, Kristo I, Riegler M. Does anti-reflux surgery disrupt the pathway of Barrett's esophagus progression to cancer? Transl Gastroenterol Hepatol 2018;3:101.
Practice? Gastroenterology 2018;154:1594-601.

48. Brar TS, Draganov PV, Yang D. Endoluminal Therapy for Gastroesophageal Reflux Disease: In Between the Pill and the Knife? Dig Dis Sci 2017;62:16-25.

49. Frazzoni M, Piccoli M, Conigliaro R, et al. Laparoscopic fundoplication for gastroesophageal reflux disease. World J Gastroenterol 2014;20:14272-9. 